Voces

\section{El patrimonio, tejido y destejido}

Cristina Cruces Roldán

Consejera del Consejo Audiovisual de Andalucia

Junto a una testaruda complejización del concepto patrimonio, se arrellanan nuevas esperanzas para un viejo motivo: la cultura. El patrimonio es expresión directa de la cultura, emana de ésta y como ella es integrado, holístico y cambiante. Material y simbólico, factual e ideal, sedimento y fractura, el patrimonio está en los sentidos y en la memoria: es la pared y la palabra, la vasija y la fiesta, la ruina y el grito. Se encarna en expresiones únicas - un vestido, una soleá, un fondo marino, un oficio- que no existen sin el escenario y la mudanza, sin la contingencia y el cambio. Como la vida, y como el poema, el patrimonio es un viejo tapiz tejido y destejido a cada instante.

En la dinámica glocal que suspende las identidades singulares y las culturas locales sobre el vértigo de la mundialización, las definiciones del patrimonio adquieren formas a veces imprecisas que van desde los simbolismos, las ideologías y las prácticas consuetudinarias, hasta la producción y el consumo culturales. Sin embargo, un capital exclusivo e intransferible se instala en el concepto y lo engrandece en las conciencias: su capacidad para sugerir un sentido último que escapa a la mercancía, que evoca hábitos humanos no utilitarios y que también se invoca como excelsa paleta de colores con que pintar la identidad personal y colectiva. El núcleo mismo con que desgajar "lo que permanece" de aquello que simplemente "se vive" cotidianamente.

En la cultura andaluza, el patrimonio no puede sino enredarse en la feliz maraña del legado histórico y de la construcción continua sobre lo no destruido. Patrimonio promiscuamente feliz que incluye la cohesión y la diversidad, lo tangible e intangible, las expresiones viejas y las producciones culturales emergentes, la pluralidad de hablas y la norma común, la memoria oral y la documentación escrita, la interculturalidad entre mayorías, viejas minorías y "nuevos andaluces". Patrimonio y modernidad no deberían correr el riesgo de aparecer como líneas paralelas, sin relación ni encuentro. Detrás de la supuesta contradicción entre los términos subyace tal vez un complejo de culpa: no haber entendido algunos patrimonios como lo que exactamente fueron, expresiones innovadoras que supieron quedarse, indisciplinadamente fieles a una tradición que quisieron transgredir con armas aleadas en la sabiduria misma de la historia.

Por eso, socializar el patrimonio es una empresa colectiva, que se pasea desde las bibliotecas a los cuentos de cabecera; desde las fábricas al disfrute de los recursos naturales; desde las salas de cine a los bailes espontáneos; desde la arquitectura tradicional al racionalismo. Comporta cuestionar a los ancestros, deconstruir la autenticidad, desvelar la contemporaneidad de tanta cultura que, como el flamenco, nació coetánea al cine, la fotografía, el impresionismo, el cubismo y las vanguardias, y que languideció entre toscas exégesis en busca de raices. $Y$ también acarrea otorgar un nuevo significado al patrimonio popular, industrial, científico o cre- ativo, desfosilizar la tradición, convertirla en una forma de comunicación interpretada con la voz de sus pueblos. Luchar con el rigor contra el estigma de los espejos cóncavos en que se reflejan simbolos y señas de identificación que sirvieron para construir una "españolidad" lisa, que condujeron a sobreidentificaciones espurias o a un primitivismo romántico provocador del desaire de los renovadores.

Hacer alta política de la cultura no sólo significa conservar, sino también dinamizar los patrimonios. Socializar el derecho a la cultura es una tarea de educación, investigación y acción administrativa. De educación de una ciudadanía convencida, mujeres y hombres que se sientan protagonistas y sujetos de una idea, que vivan las experiencias del patrimonio como ámbitos de significación y mediación, que no consideren un problema conservar patrimonios cuyos beneficios puedan revertir en la felicidad de (casi) todos. El primer nivel de conservación del patrimonio es la representación del propio conocimiento. De confección de protocolos, de una intervención que comprometa medios y garantice evaluaciones, resultados y continuidad a los trabajos de calidad, que implique a los profesionales adecuados a cada materia para sumar asi sus miradas de ojo de perdiz. De tratamiento administrativo del paisaje y la cultura como interdependencias necesarias, para aprehender prácticas y modos de vida acontecidos en espacios que han sido interpretados por una comunidad y definidos por la estratigrafía de sus tiempos acumulados. De acción preventiva y ejecutiva -inventario y protección- y de transferencia a la sociedad de los resultados y las oportunidades que el patrimonio ofrece.

Investigar, difundir, conservar... y desarrollar. El desarrollo es no someter al patrimonio a la economización de la cultura, pero tampoco renunciar a su capacidad creadora de utilidades. Y éstas van más allá de la categorización ramplonamente económica del concepto: incluyen valores de excelencia no siempre transferibles y enajenables en términos de acumulación o beneficio monetarios, pero que también son -etimológicamente- económicos. El patrimonio, la cultura, no sólo crean utilidades; crean conciencia para la vivencia y la convivencia. El comprometido "desarrollo sostenible" también anida aquí, y ni el conservacionismo innegociable ni el urgentismo del beneficio pueden guiar lateralmente los modelos a seguir.

Del mismo modo que existen derechos sobre el patrimonio, también los hay de, desde y para el patrimonio. La reclamación de los derechos patrimoniales significa reclamar unos derechos culturales que son legítimo fideicomiso para las generaciones por venir y que deben generar, también diferidamente, bienestar y calidad de vida. El patrimonio está obligado a ampliar su vocación de reflejo de identidad para servir también como fuente de identidad en el encuentro compartido de una cultura común. 